\title{
Optimizing Multi-Item EOQ when the Constraint of Annual Number of Orders is Active
}

\author{
Karzan Mahdi Ghafour ${ }^{1} \&$ Rezan Hama Rashid ${ }^{1}$ \\ ${ }^{1}$ School of Administrations and Economics, University of Sulaimani, Iraq \\ Correspondence: Karzan Mahdi Ghafour, School of Administrations and Economics, University of Sulaimani, \\ Kurdistan Region, Iraq. Tel: 9647-701-493-330 E-mail: karzan.ghafour@gmail.com
}

Received: August 8, 2017

Accepted: September 9, 2016

Online Published: October 5, 2016

doi:10.5539/mas.v11n1p55

URL: http://dx.doi.org/10.5539/mas.v11n1p55

\begin{abstract}
The responsibility in inventory models decides of how much or how many of inventory items to order. An economic order quantity (EOQ) differs from a model to another according to the assumptions and the variables. This paper has developed the EOQ in two deterministic inventory model (Purchases with shortage and production with shortage) of multi-item when the objective function is subjected to annual number of orders. The constraints are assumed to be active if the left hand side does not satisfy the right hand side condition. Thus, Lagrange method is used to find the new multi-item EOQ in each two models with the constraint to achieve the new formula of EOQ. Finally, a numerical example is provided to justify the proposed model.
\end{abstract}

Keywords: deterministic inventory models, EOQ, Lagrange method

\section{Introduction}

Since nearly a century ago, the model of economic order quantity (EOQ) was proposed by (Harris, 1913). Almost five years later, the model of production quantity (EPQ) was proposed by (Taft, 1918). Later, Hadley and Whitin (1963) proposed model of EOQ/EPQ. The policy of inventory control is interested basically with two traditional decisions 'How much to order (produce or purchase) to replenish the inventory of an item and when to order". Many models of inventory have been developed to answer these two questions. The perfect order quantity is the primal assumption of the classical economic order quantity (EOQ). But due to the large number of factors that cannot be avoided, this assumption may not be valid always for most of production ergonomics. However, most of the offered inventory models are developed in the deterministic ergonomics (Khan, Jaber, Guiffrida, et al., 2011; Pentico \& Drake, 2011; Yousefli and Ghazanfari, 2012). The basic premise of the EOQ is that the stock-out is not allowed. Moreover, the assumption of the demand and the lead-time are constant and known. The EOQ model sees the tradeoff between ordering and depot cost in choosing the quantity to use inventory of replenish item. A large order quantity will decrease ordering repetition; hence reducing the cost of the order per unit time, on the other hand, increasing depot holding cost. Contrary, small order quantity decreases the holding cost but increases the ordering frequency as well as cost per unit time. The order quantity which minimizes the cost is called Economic Order Quantity (EOQ). For many years, the problem of classical EOQ discussed with variety forms and resolved by many researches in books references, articles, etc. e.g., (Frederick \& Gerald, 2001; Hamdy, 2007; Schwarz, 1972). It starts from a simple model of single-item with related demand to unit price Cheng (1989) until multi-item with many constraints. These processors are fully analytical and involve much arithmetic effort to get the optimality solution.

Goyal and Cárdenas-Barrón (2002) introduced a simple approach for determining the EPQ of a product with defective quality. They presented that near-optimal results are obtained by using the simple approach. The model suggested in their note is easier to implement.

Rezaei,(2005), Papachristos and Konstantaras (2006), Wee et al. (2007) and Chang and Ho (2010) studied the problem by considering the occurrence of shortage. Khan, Jaber and Bonney (2011) developed a mathematical model of inspection which consists of three costs: inspection cost, cost error of type I and cost error of type II. Rezaei (2014) proposed a general mathematical model, which used for various types of growing products, followed by a particular mathematical model for specific type of poultry.

This paper aims to develop a mathematical model in a deterministic inventory models (Purchases with Shortage 
and Production with Shortage) to determine a new formula of EOQ in multi-item when the objective function is subjected to the number of order per year constraint. This condition can be achieved when the left hand side of the constraint is not satisfy the right hand side, in another interpretation, the left hand side is greater than the right hand side which mean the constraint is active. However, in a previous work we developed a new formula of EOQ in multi-items when the objective function is subjected to investment and capacity of shortage space constraints and we presented a numerical example to show the effect of the constraints on EOQ when it is active and the changes in the value of EOQ (Ghafour et al., 2015). Therefore, this paper is an extension of the paper aforementioned to establish a new formula of EOQ in the same deterministic inventory models (Purchases with Shortage and Production with Shortage) when the constraint of number of annual order is active.

\section{Problem Description and Assumptions}

This paper investigated on the deterministic multi item models in inventory control, which are intended, the classical economic order quantity, EOQ. The models of deterministic in inventory control divided into four models with constant demand rate and zero lead-time assumption (Buzacott, 1975; Chung \& Liao, 2004; Ghare \& Schrader, 1936; Ray \& Chaudhuri, 1997; Schwarz, 2008; Schwarz, 1972). However, this paper investigated the deterministic multi item inventory control models (purchase with shortage and production with shortage) to establish a new formula of EOQ subjected to number of annual order. To start classify these models in deterministic inventory control there are some assumptions and notations as follows:

\section{Assumption}

The following assumptions are made to develop the model

The replenishment is instantaneous for model 1.

The replenishment is gradually for model 2 .

The demand is constant and known.

The lead-time equal to zero.

The shortage is allowed for both models.

\section{Notations}

$Q \quad$ Economic order quantity/ order.

$Z$ Total inventory cost.

$K$ Setup cost/ per order

$h$ Holding cost/ per unit and time $=I^{*} C$

C Unit cost.

I Inventory holding cost percentage (\%).

$p$ Cost of shortage per unit and unit time.

$\beta$ Demand rate per unit and unit time.

$\alpha$ Production rate / per unit per unit time.

$S$ Maximum shortage quantity.

\subsection{First Model, Purchases with Shortage}

Shortage assumption is allowable in this model. Practically, when the inventory cannot satisfying the retailers demand, the concerned authority will face to pay off the required quantities, which mean access the shortage, and this shortage lead to fines imposition for the failure to meet the needs of the concerned authority. The shortage can be loss profit or loss of the quantity in the store. Therefore, this model aims to find the optimal EOQ and in the same time the maximum shortage quantity that can be expected. The EOQ equation for this model is:

$$
\begin{gathered}
Q^{*}=\sqrt{\frac{2 K \beta(p+h)}{h p}} \\
S^{*}=\sqrt{\frac{2 K \beta h}{p(p+h)}}
\end{gathered}
$$




$$
Z=\frac{k \beta}{Q}+h \frac{(Q-S)^{2}}{2 Q}+p \frac{S^{2}}{2 Q} \quad \text { or } Z=\sqrt{\frac{2 k \beta b p}{(p+h)}+c \beta}
$$

\subsection{Second Model, Production with Shortage}

The assumption of this model allows the shortage happen as the previous model. Moreover, the replenishment is gradually. Therefore, the Equations of EOQ, maximum shortage and total cost function are as follow:

$$
\begin{gathered}
Q^{*}=\sqrt{\frac{2 K \beta(p+h)}{h b p}} \\
S^{*}=\sqrt{\frac{2 K \beta h b}{h(p+h)}} \\
Z=\frac{k \beta}{Q}+h \frac{(Q b-S)^{2}}{2 Q b}+p \frac{S^{2}}{2 Q b} \quad \text { or } Z=\sqrt{\frac{2 k \beta h b p}{(p+h)}}+c \beta
\end{gathered}
$$

Where, $b=\left(1-\frac{\beta}{\alpha}\right)$

\section{Methodology}

This paper considered two deterministic multi-item inventory models (purchase with shortage and production with shortage) with constant demand and zero lead-time assumptions. In the model description the Equation EOQ represented for single item, which mean $(j=1)$ where, $j$ is the number of items. However, when $(n>1)$, i.e., for more than one item (multi-item) with the existence of number of annual orders constraints. This led us to some additional notation.

$Q_{j}=$ the EOQ for each item $j, j=1,2, \ldots ., n$

$Z_{j}=$ the total cost for each item $j, j=1,2, \ldots, n$

$A_{I}=$ maximum value of order per year

$D_{j}=$ the number of order for each item $j, j=1,2, \ldots, n$

In the same vein, all other variables as we noted previously will change for multi-item $(j, j=1,2, \ldots, n)$.

Therefore, the constraint of number of orders per year can be presented as follows:

$$
\sum_{j=1}^{n} \frac{D_{j}}{Q_{j}} \leq A_{1}
$$

The constraint of number of annual orders in the considered multi-item inventory models achieved when the left hand side of Equation (7) does not satisfy the right hand side, i.e. when it is greater than the right hand side, therefore, the constraints is active. Hence replace the EOQ $(Q)$ in Equations (1) and (4) by $\left(Q_{j}\right)$ for multi-item. In this situation we need to fine the new value of $\left(Q_{j}\right)$ and this done by using Lagrange method.

$$
L(x, \lambda)=f(x)-\lambda\left(g(x)-b_{i}\right)
$$

Where, $f(x)$ is the objective function (total cost function) for the two models as Equations (3) and (6) and $\left(g(x)-b_{i}\right)$ represents the constraint as in Equation (7).

\subsection{First Model with the Constraint}

To establish a new formula of multi-item EOQ when the constraint number of annual orders is active, we integrate Equations (3) and (7) in Equation (8) as follows: 


$$
\begin{gathered}
L(Q, \lambda)=\frac{k_{j} \beta_{j}}{Q_{j}}+h_{j} \frac{\left(Q_{j}-S\right)^{2}}{2 Q_{j}}+P_{j} \frac{S^{2}}{2 Q_{j}}-\lambda\left(\sum_{j=1}^{n} \frac{D_{j}}{Q_{j}}-A_{1}\right) \\
\frac{\partial}{\partial Q}=\frac{-k_{j} \beta_{j}}{Q_{j}^{2}}+\frac{h_{j}}{2}\left(\frac{2\left(Q_{j}-S\right) Q_{j}\left(Q_{j}-S\right)^{2}-}{Q_{j}^{2}}\right)-P_{j} \frac{S^{2}}{2 Q_{j}}-\lambda \frac{D_{j}}{Q_{j}^{2}}=0
\end{gathered}
$$

Multiply Equation (10) by $Q_{j}^{2}$, we obtain,

$$
\begin{gathered}
-k_{j} \beta_{j}+\frac{h_{j}}{2}\left(2 Q_{j}-S\right) Q_{j}-\left(Q_{j}-S\right)^{2}-P_{j} \frac{S^{2}}{2}-\lambda D_{j} \\
-k_{j} \beta_{j}+\frac{h_{j}}{2}\left(2 Q_{j}-2 Q_{j} S-Q_{j}^{2}+2 Q_{j} S-S\right)^{2}-\frac{P_{j} S^{2}}{2}-\lambda D_{j}=0 \\
-k_{j} \beta_{j}+\frac{h_{j}}{2}\left(Q_{j}^{2}-S^{2}\right)-\frac{P_{j} S^{2}}{2}-\lambda D_{j}=0
\end{gathered}
$$

Multiply Equation (11) by 2, we obtain,

$$
\begin{aligned}
& h_{j} Q_{j}^{2}-h_{j} S^{2}-2 \lambda D_{j}=2 k_{j} \beta_{j}+P_{j} S^{2} \\
& \therefore Q_{j}=\sqrt{\frac{2 k_{j} \beta_{j}+P_{j} S^{2}+h_{j} S^{2}-2 \lambda D_{j}}{h_{j}}}
\end{aligned}
$$

Equation (12) represents the new formula of multi-item EOQ in the inventory model of purchase with shortage when the constraint of number of annual orders is active. However, the problem in Equation (12) is the value of Lambda which is unknown. There are two ways to find the value of Lambda, $\lambda$. The first way is by using the trial and error compensation method by giving a value to $\lambda$ starting with zero until achieves the constraint condition or be as close as possible, whether positive or negative. The second way is by using the scientific method, which is more accurate by considering the derivation method as follows:

$$
\sum_{j=1}^{n} \frac{D_{j}}{\sqrt{\frac{2 k_{j} \beta_{j}+P_{j} S^{2}+h_{j} S^{2}-2 \lambda D_{j}}{h_{j}}}}=A_{1}
$$

Where, $h_{j}=I_{j} * C_{j}$

$$
\begin{aligned}
\sum_{j=1}^{n} \frac{D_{j}}{\sqrt{\frac{2 k_{j} \beta_{j}+P_{j} S^{2}+I_{j} C_{j} S^{2}-2 \lambda D_{j}}{I_{j} C_{j}}}} & =A_{1} \Rightarrow \sqrt{2 \lambda D_{j}}=\frac{D_{j}}{A_{1}} \sqrt{2 k_{j} \beta_{j}+P_{j} S^{2}+C_{j} S^{2}} \\
\lambda & =-\frac{\left(\frac{1}{A_{1}^{2}} \sqrt{2 k_{j} \beta_{j}+P_{j} S^{2}+C_{j} S^{2}}\right)^{2}}{2}
\end{aligned}
$$

\subsection{Second Model with Constraint}

To establish a new formula of multi-item EOQ when the constraint of number of annual orders is active, by the similar approach as in previous section we integrate Equations (6) and (7) in Equation (8) as follows:

$$
L(Q, \lambda)=\frac{k_{j} \beta_{j}}{Q_{j}}+h_{j} \frac{\left(Q_{j} b_{j}-S\right)^{2}}{2 Q_{j} b_{j}}+P_{j} \frac{S^{2}}{2 Q_{j} b_{j}}-\lambda\left(\sum_{j=1}^{n} \frac{D_{j}}{Q_{j}}-A_{2}\right)
$$




$$
\begin{gathered}
\frac{\partial L}{\partial Q}=\frac{-k_{j} \beta_{j}}{Q_{j}^{2}}+\frac{h_{j}}{2 b_{j}}\left(\frac{2 Q_{j} b_{j}\left(Q_{j} b_{j}-S\right)-\left(Q_{j} b_{j}-S\right)^{2}}{Q_{j}^{2}}\right)+P_{j} \frac{S^{2}}{2 Q_{j} b_{j}}-\lambda D_{j}=0 \\
\frac{\partial}{\partial \lambda}=b_{1}-\frac{D_{j}}{Q_{j}}=0 \\
-k_{j} \beta_{j} b_{j}+\frac{h_{j}}{2 b_{j}}\left(2 Q_{j} b_{j}^{2}-S\right) Q_{j}-\left(Q_{j}-S\right)^{2}+P_{j} \frac{S^{2}}{2}-\lambda D_{j} Q_{j}^{2}
\end{gathered}
$$

Multiply Equation (16) by $Q_{j}^{2} b_{j}$, we obtain,

$$
\begin{gathered}
-k_{j} \beta_{j}+\frac{h_{j}}{2 b_{j}}\left(2 Q_{j}^{2} b_{j}^{2}-2 Q_{j} b_{j} S-2 Q_{j} b_{j} S-Q_{j}^{2} b_{j}^{2}+2 Q_{j} b_{j} S-S^{2}\right)+ \\
\frac{P_{j} S^{2}}{2 Q_{j}^{2} b_{j}}-\lambda D_{j} Q_{j}^{2} b_{j}=0 \\
-k_{j} \beta_{j}+\frac{h_{j}}{2}\left(Q_{j}^{2} b_{j}^{2}-S^{2}\right)-\frac{P_{j} S^{2}}{2}-\lambda D_{j} Q_{j}^{2} b_{j}=0, \\
h_{j} Q_{j}^{2} b_{j}^{2}-h_{j} S^{2}-2 \lambda D_{j} Q_{j}^{2} b_{j}=2 k_{j} \beta_{j} b_{j}+P_{j} S^{2} \\
\therefore Q_{j}=\sqrt{\frac{2 k_{j} \beta_{j} b_{j}+P_{j} S^{2}+h_{j} S^{2}-2 \lambda D_{j} b_{j}}{h_{j} b_{j}}}
\end{gathered}
$$

Equation (17) represents the new formula of multi-item EOQ in the inventory model of production with shortage when the constraint of number of annual orders is active. The same problem appears as Equation (12), which is the value of Lambda. However, by the similar approach as Equation (14) we can extract the value of Lambda, $\lambda$

$$
\sum_{j=1}^{n} \frac{D_{j}}{\sqrt{\frac{2 k_{j} \beta_{j} b_{j}+P_{j} S^{2}+h_{j} S^{2}-2 \lambda D_{j} b_{j}}{h_{j} b_{j}}}}=A_{2}
$$

where, $h_{j}=I_{j} * C_{j}$

$$
\begin{gathered}
\sum_{j=1}^{n} \frac{D_{j}}{\sqrt{\frac{2 k_{j} \beta_{j} b_{j}+P_{j} S^{2}+I_{j} C_{j} S^{2}-2 \lambda D_{j} b_{j}}{I_{j} C_{j} b_{j}}}}=A_{2} \Rightarrow \sqrt{b_{j}-2 \lambda D_{j}}=\frac{D_{j}}{A_{2}} \sqrt{2 k_{j} \beta_{j}+P_{j} S^{2}+S^{2}} \\
\lambda=-\frac{\left(\frac{1}{A_{2}^{2}} \sqrt{2 k_{j} \beta_{j}+P_{j} S^{2}+S^{2}}\right)^{2}}{2}
\end{gathered}
$$

\section{Numerical Example}

Example: To illustrate the result of above theory, we used our previous example in (Ghafour et al., 2015).The parameters illustrate the concept of first model with total annual number of orders. However, Table 1 shows all the parameters of the model with total allowed number of orders is equal to 7 .

Table 1. Given parameters of the three items with total allowed number of orders is equal to 7

\begin{tabular}{lllllll}
\hline Items & $\boldsymbol{\beta}_{\boldsymbol{i}}$ & $\boldsymbol{K}_{\boldsymbol{i}}(\$)$ & $\boldsymbol{h}_{\boldsymbol{i}}(\$)$ & $\boldsymbol{C}_{\boldsymbol{i}}(\$)$ & $\boldsymbol{P}_{\boldsymbol{i}}(\$)$ & $\boldsymbol{S}_{\boldsymbol{i}}$ \\
\hline 1 & 33 & 25 & 1 & 1 & 3 & 14 \\
2 & 24 & 18 & 1.5 & 0.5 & 6 & 13 \\
3 & 20 & 20 & 2 & 2.5 & 8 & 12 \\
\hline
\end{tabular}


First of all, we find the $Q_{j}$ for the three items by applying Equation (12) assuming $\lambda=0$ to show the constraint is active or not. Therefore, $Q_{1}=49.34 /$ week, $Q_{2}=37.70 /$ week and $Q_{3}=33.47 /$ week. Thus,

$\sum_{j=1}^{3} C_{j} Q_{j} \leq A_{1} \Rightarrow 7.7 \leq 7$. When the constraint is not satisfying the condition, means the constraint is active. Therefore, we should fine the new $Q_{j}$ for each item with the new value of Lambda. See Table 2 for results.

Table 2. Results of the new $Q_{j}$ when $\lambda=-0.231$

\begin{tabular}{|c|c|c|}
\hline Items & $Q_{j}$ & \multirow{4}{*}{$\sum_{j=1}^{3} \frac{D_{j}}{Q_{j}}=6.09 \leq A_{1}=7$} \\
\hline 1 & 49.80161 & \\
\hline 2 & 50.32971 & \\
\hline 3 & 47.86251 & \\
\hline
\end{tabular}

Depending on the allowable total investment, the values of the EOQ decreased for each item. These new values of EOQ are optimal when $\lambda=-0.231$, which means optimal exploitation of the annual number of orders.

\section{Discussion}

The deterministic inventory models (purchase with shortage and production with shortage) has developed and analyzed when they are subjected to annual number of orders or value of EOQ. The numeric advantage of using these equations are very important and necessary when we cannot exceed the total annual number of demand, therefore, we must extract these new equations of the EOQ for optimum exploitation of the annual number of orders also do not exceed the constraint. The findings show that, the constraint with each inventory models that we presented can help the decision maker to find the optimal EOQ for each item in each model by using Lagrange method, thus, the optimal quantity of shortage and the minimum total cost. The new EOQ can be applied in many real situations like general warehouses, storage in supermarkets, production storage which stores more than one item and need more space and specific decisions about the EOQ. For the future work we suggest to find the new EOQ in each of the four models (purchases without shortage, production without shortage, purchases with shortage and production with shortage) when they are subjected to number of items constraint.

\section{References}

Buzacott, J. A. (1975). Economic order quantities with inflation. Operational research quarterly. Operations Research Quarterly, 26, pp. 553-558. http://dx.doi.org/10.1057/jors.1975.113

Chang, H. C., \& Ho, C. H. (2010). Exact closed-form solutions for 'optimal inventory model for items with imperfect quality and shortage backordering'. Omega, Elsevier, 38(3), pp. 233-237. http://dx.doi.org/10.1016/j.omega.2009.09.006

Chung, K. J., \& Liao, J. J. (2004). Lot-sizing decisions under trade credit depending on the ordering quantity. Computers \& Operations Research, 31(6), pp. 909-928. http://dx.doi.org/10.1016/S0305-0548(03)00043-1

Frederick, S. H., \& Gerald, J. L. (2001). Introduction To Operations Research. (7th Ed.) McGraw-Hill, New York.

Ghafour, K. M., Ramli, R., \& Zaibidi, N. Z. (2015). Development of multi-item EOQ when the constraints of investment and storage capacity are active. AIP Conference Proceedings, 1691. http://dx.doi.org/10.1063/1.4937024

Ghare, P. M., \& Schrader, G. F. (1936). A model for exponentially decaying inventory. Journal of Industrial Engineering, 14(5), pp. 238-243.

Goyal, S. K., \& Cárdenas-Barrón, L. E. (2002). Note on: economic production quantity model for items with imperfect quality-a practical approach. International Journal of Production Economics, Elsevier, 77(1), pp. 85-87. http://dx.doi.org/10.1016/S0925-5273(01)00203-1

Hadley, G., \& Whitin, T. M. (1963). Analysis of inventory systems. In E. Cliffs (Ed.), Prentice Hall, New Jersey.

Hamdy, A. T. (2007). Operations Research an introduction. In H. Stark (Ed.), (7th Ed.). Pearson Prentic Hall.

Harris, F. W. (1913). How many parts to make at once. Magazine of Management, 10, pp. 135-136. http://dx.doi.org/10.1287/opre.38.6.947 
Khan, M., Jaber, M. Y., \& Bonney, M. (2011). An economic order quantity (EOQ) for items with imperfect quality and inspection errors. International Journal of Production Economics, Elsevier, 33(1), pp. 113118.DOI: 10.1016/j.jpe.2010.01.023

Khan, M., Jaber, M. Y., Guiffrida, A. L., \& Zolfaghari, S. (2011). A review of the extensions of a modified EOQ model for imperfect quality items. International Journal of Production Economics, 132(1), pp. 1-12. http://dx.doi.org/10.1016/j.ijpe.2011.03.009

Papachristos, S., \& Konstantaras, I. (2006). Economic ordering quantity models for items with imperfect quality. International Journal of Production Economics, Elsevier, 100(1), pp. 148-154. http://dx.doi.org/10.1016/j.ijpe.2004.11.004

Pentico, D. W., \& Drake, M. J. (2011). A survey of deterministic models for the EOQ and EPQ with partial backordering. European Journal of Operational Research, Elsevier, 214(2), pp. 179-198. http://dx.doi.org/10.1016/j.ejor.2011.01.048

Ray, J., \& Chaudhuri, K. S. (1997). An EOQ model with stock-dependent demand, shortage, inflation and time discounting", International Journal of Production Economics, 53(2), pp. 171-180. http://dx.doi.org/10.1016/S0925-5273(97)00112-6

Rezaei, J. (2005). Economic order quantity model with backorder for imperfect quality items. Proceedings of IEEE International Engineering Management Conference, pp. 466-470.

Rezaei, J. (2014). Economic order quantity for growing items. International Journal of Production Economics, Elsevier, 155, pp. 109-113. http://dx.doi.org/10.1016/j.ijpe.2013.11.026

Schwarz, L. (2008). The Economic Order-Quantity (EOQ) Model. In D. Chhajed, \& T. Lowe, (Eds.), Building Intuition SE-8, International Series in Operations Research \& Management Science, Springer US, 115, pp. $135-154$.

Schwarz, L. B. (1972). Economic Order Quantities for Products with Finite Demand Horizons. A I I E Transactions, Taylor \& Francis, 4(3), pp. 234-237. http://dx.doi.org/10.1080/05695557208974855

Taft, E. W. (1918). The most economical production lot. Iron Age, 101(18), pp. 1410-1412.

Wee, H. M., Yu, J., \& Chen, M. C. (2007). Optimal inventory model for items with imperfect quality and shortage backordering. Omega, Elsevier, 35(1), pp. 7-11. http://dx.doi.org/10.1016/j.omega.2005.01.019

Yousefli, A., \& Ghazanfari, M. (2012). A Stochastic Decision Support System for Economic Order Quantity Problem. Advances in Fuzzy Systems, 2012, pp. 1-8. http://dx.doi.org/10.1155/2012/650419

\section{Copyrights}

Copyright for this article is retained by the author(s), with first publication rights granted to the journal.

This is an open-access article distributed under the terms and conditions of the Creative Commons Attribution license (http://creativecommons.org/licenses/by/4.0/). 